\title{
Resveratrol represses YKL-40 expression in human glioma U87 cells
}

Wei Zhang ${ }^{1,2 \dagger}$, Koji Murao $^{3 \dagger}$, Xiang Zhang ${ }^{1 \dagger}$, Kensuke Matsumoto ${ }^{3}$, Suwarni Diah ${ }^{4}$, Masaki Okada ${ }^{2}$, Keisuke Miyake ${ }^{2}$, Nobuyuki Kawai ${ }^{2}$, Zhou Fei ${ }^{i^{*}}$, Takashi Tamiya ${ }^{2^{*}}$

\begin{abstract}
Background: Glioblastoma multiforme (GBM) is the most malignant intracranial tumour that develops in both adults and children. Microarray gene analyses have confirmed that the human YKL-40 gene is one of the most over-expressed genes in these tumours but not in normal brain tissue. Clinical studies have shown that serum YKL-40 levels are positively correlated with tumour burden in addition to being an independent prognostic factor of a short relapse-free interval as well as short overall survival in patients with various cancers. Our previous study revealed that YKL-40 was closely correlated with the pathological grades of human primary astrocytomas and played a crucial role in glioma cell proliferation. Hence, YKL-40 could be an attractive target in the design of anticancer therapies.
\end{abstract}

Methods: Cell viability and invasion assays were performed to detect the cell proliferation and invasive ability of U87 cells induced by resveratrol (3, 5, 4'-trihydroxystilbene; Res) or YKL-40 small-interfering RNAs (siRNAs). In addition, the luciferase assay, real-time RT-PCR, western blotting, and ELISA were used to measure YKL-40 promoter activity, mRNA, and protein expression, respectively. The expressions of phosphor-ERK1/2 and ERK1/2 were determined by western blotting.

Results: Res inhibited U87 cell proliferation and invasion in vitro and repressed YKL-40 in U87 cells by decreasing the activity of its promoter and reducing mRNA transcription and protein expression in vitro. YKL-40 siRNA treatment also impaired the invasiveness of U87 cells. When U87 cells were cultured with 20 MM PD98059 (an ERK1/2 inhibitor) alone, with $20 \mu \mathrm{M}$ PD98059 and $100 \mu \mathrm{M}$ Res, or with $100 \mu \mathrm{M}$ Res alone for $48 \mathrm{~h}$, YKL-40 protein expression decreased most significantly in the Res-treated group. PD98059 partially reversed the decrease of YKL-40 protein expression induced by Res. Furthermore, phosphor-ERK1/2 expression was reduced by Res treatment in a time-dependent manner.

Conclusions: We demonstrated for the first time that Res represses YKL-40 expression in vitro; in addition, the ERK1/2 pathway is involved in this repression. This finding could extend the prospective use of Res in glioma research and enlarge the armamentarium for treating gliomas.

\section{Background}

Malignant gliomas are the most common type of primary malignant brain tumours and are almost always lethal in both adults and children despite the existence of therapies, which include surgery, radiotherapy, and

\footnotetext{
* Correspondence: feizhou@fmmu.edu.cn; tamiya@kms.ac.jp

† Contributed equally

'Department of Neurosurgery, Xijing Hospital, The Fourth Military Medical University, 127 West Changle Road, Xi'an, Shaanxi Province, 710032, People's Republic of China

${ }^{2}$ Department of Neurological Surgery, Faculty of Medicine, Kagawa University, 1750-1 Ikenobe, Miki-cho, Kida-gun, Kagawa 761-0793, Japan Full list of author information is available at the end of the article
}

chemotherapy. Patients with GBM have an average survival time of 12 to 18 months from initial diagnosis and 6 to 9 months after recurrence $[1,2]$.

In recent years, literature reviews of patients with various types of cancer (breast, colorectal, ovarian, kidney, prostate, small-cell lung, melanoma, and glioma) suggest that the serum YKL-40 level detected with the enzymelinked immunosorbent assay (ELISA) could be a promising predictor of tumour burden and an independent prognostic variable of a short relapse-free interval as well as short overall survival [3-12]. More importantly, an elevated plasma YKL-40 level could predict an

\section{() Biomed Central}


increased risk of gastrointestinal cancer after diagnosis of any other cancer [13].

Over a decade ago, YKL-40 was identified in vitro as a secreted glycoprotein in the culture medium of the human osteosarcoma cell line MG63 [14]. It contains an open reading frame of 383 amino acids and has a molecular weight of $40,476 \mathrm{kDa}$ [15]. The gene encoding YKL-40 is located on chromosome 1q31-q32. The Sp1family transcription factors predominantly regulate YKL-40 promoter activity during human macrophage differentiation [16]. Although the biological function of YKL-40 in cancer remains largely unclear, studies have suggested that YKL-40 may play a positive role in cancer cell survival and differentiation, protection against apoptosis, angiogenesis stimulation, and regulation of extracellular tissue remodeling [17-19]. Regarding gliomas, microarray gene analyses have revealed that the human YKL-40 gene is one of the most over-expressed genes in GBM, but it is not expressed in normal brain tissue $[10,20]$. Furthermore, our previous study indicated that silencing the YKL- 40 gene could significantly attenuate glioma cell proliferation by arresting the cell cycle in the $G_{1}$ phase [21]. Therefore, YKL-40 is an attractive target in the design of anti-cancer therapies. However, to date, there is no documentation on targeting YKL-40 expression for development of a novel adjuvant glioma therapy.

In 2007, we reported that a polyphenolic natural product, resveratrol (Res), inhibited cell growth and induced apoptosis of C6 glioma cells in rats but not in normal 3 T3 fibroblast cells [22]. In in vivo studies, Res slowed the growth of subcutaneous gliomas in rats [23], prolonged survival time, and increased the survival rate in a rat glioma model [24]. Thus, Res has significant potential clinical applications in the treatment of gliomas. On the basis of existing literature reports and our previous studies, we hypothesize that Res might repress YKL-40 expression, and the findings of the present study have confirmed this to be the case. To the best of our knowledge, this is the first report indicating that Res could be a potential candidate targeting YKL-40 expression.

\section{Methods}

\section{Cell lines and culture}

A human glioblastoma cell line, U87, was purchased from the American Type Culture Collection (ATCC; Manassas, VA, USA). The tumour cell line was maintained in minimum essential medium (MEM) (Gibco Life Science, Gaithersburg, MD, USA) supplemented with $10 \%$ fetal bovine serum (Gibco Life Science), $2 \mathrm{mM}$ L-glutamine, 100 units $/ \mathrm{ml}$ penicillin, and $100 \mu \mathrm{g} / \mathrm{ml}$ streptomycin. All cells were cultured at $37^{\circ} \mathrm{C}$ in a $5 \%$ $\mathrm{CO}_{2}$ incubator.

\section{Cell viability assay}

Cell proliferation was determined by using a WST-1 cell proliferation reagent (Roche Applied Science, Mannheim, Germany). In brief, $2 \times 10^{4}$ cells were seeded in a flatbottomed 96-well plate (Nunc, Roskilde, Denmark) and cultured for $24 \mathrm{~h}$ to reach $60 \%$ to $70 \%$ confluence prior to Res treatment. Res (Sigma, St Louis, MO, USA) was dissolved in dimethylsulfoxide (DMSO; Wako, Osaka, Japan) to a stock concentration of $1 \mathrm{mM}$ and subsequently diluted with culture medium to final concentrations of $0,1,10$, and $100 \mu \mathrm{M}$ just before use. The concentration of DMSO in the vehicle was 1:1000. The cells were exposed to the indicated concentrations of Res for $0,24,48$, and $72 \mathrm{~h}$. Each group was set in 8 wells. At each time point, $10 \mu \mathrm{l} /$ well WST-1 reagent cultured at $37^{\circ} \mathrm{C}$ for $4 \mathrm{~h}$ was added. The optical density was measured at $460 \mathrm{~nm}$. The cell growth curves were drawn according to the optical density of each group of cells. The trypan blue dye cell exclusion assay was used to determine cell viability by treating the cells with different dosages of Res for $48 \mathrm{~h}$. Cell viability is described as a percentage of the DMSO control group, which was set as $100 \%$. All experiments were performed in triplicate.

\section{Cell transfection and the siRNA method}

Cells were seeded at a concentration of 2.5-5 $\times 10^{4}$ cells $/ \mathrm{ml}$ and cultured for $24 \mathrm{~h}$ in 6 -well plates in order to reach $60 \%$ to $70 \%$ confluence before transfection. The cells were then transfected with $20 \mathrm{nM} S M A R T$ pool $^{\circ}$ Reagents YKL-40 or non-targeting (random) siRNA (Dharmacon, Lafayette, CO, USA) in the presence of lipofectamine 2000 (Invitrogen, Carlsbad, CA, USA) according to the manufacturer's instructions. In brief, lipofectamine (Invitrogen) and YKL-40 siRNA or negative control siRNA were dissolved separately in antibiotic- and serum-free MEM. After $10 \mathrm{~min}$ of equilibration at room temperature, each RNA solution was combined with the respective volume of lipofectamine solution, mixed gently, and allowed to form siRNA liposomes for 20-30 min at room temperature. After the cells were washed 3 times with PBS, the $200 \mu \mathrm{l} /$ well siRNA liposome mixture was added followed by the addition of $800 \mu \mathrm{l} /$ well antibiotic- and serum-free MEM. The cells were incubated for $4 \mathrm{~h}$, and the media were subsequently changed to antibiotic- and serum-containing MEM.

\section{Cell invasion assay}

The cell invasion assay was carried out using modified Boyden chambers consisting of transwell-precoated matrigel membrane filter inserts with $8-\mu \mathrm{m}$ pores in 24well tissue culture plates (BD Biosciences, San Diego, CA, USA). U87 cells were pretreated with $100 \mu$ M Res 
or YKL-40 siRNA for $48 \mathrm{~h}$. The cells were then seeded and plated at $5 \times 10^{4}$ cells/well in the upper transwell chambers of inserts precoated with matrigel in serumand growth-factor-free medium. The bottoms of the chambers were filled with $500 \mu \mathrm{l}$ medium containing $10 \%$ FBS. After 24 or $48 \mathrm{~h}$, matrigel-precoated inserts were fixed and stained with Diff-Quick Fixative Solutions (Dade Behring, Newark, DE, USA). Attached cells were imaged with an Olympus digital camera mounted to a light microscope and quantified using ImageJ software http://rsb.info.nih.gov/ij/. Invasion was calculated as the ratio of the number of invading cells to the total number of cells in both sides of the membrane. Cells were counted in triplicate membranes.

\section{Transfection of U87 cells and luciferase reporter gene assay}

The YKL-40 promoter was cloned with PCR from human genomic DNA using the following oligonucleotides: sense 5'-TAT CTG GTA CCG TGC AGG AGT GGG AGG AAG G-3' and anti-sense 5'-GAT CTA AGC TTC ATT CTG GCT GCA GCA GAG C-3'. The sequences were obtained from the published human YKL-40 promoter sequence [15]. The resultant 380-bp fragment was inserted into the KpnI and HindIII sites of the PGV-B2-basic luciferase reporter vector (ToyoInk, Tokyo, Japan), which contains the human YKL-40 gene sequences spanning the region between -377 and $2 \mathrm{bp}$. Purified reporter plasmids were then transfected into U87 cells via the lipofectamine (Invitrogen, Carlsbad, CA, USA) transfection method. Reporter plasmid-transfected U87 cells were subsequently treated with $100 \mu \mathrm{M}$ Res for $48 \mathrm{~h}$. All assays were corrected for total amounts of protein per reaction. Transfected cells were harvested in an aliquot of the cytoplasmic fraction. For the luciferase assay, $40 \mu \mathrm{l}$ aliquots were taken and the assay was carried out according to the manufacturer's instructions (Toyolnk).

\section{Real-time quantitative reverse transcript-polymerase chain reaction}

Total RNA was extracted with Isogen (Nippon Gene, Toyama, Japan), according to the manufacturer's instructions. cDNA was generated with the First-strand cDNA Synthesis Kit (Amersham Biosciences, Piscataway, NJ, USA), according to the manufacturer's instructions. Total RNA $(1 \mu \mathrm{g})$ was used for each reaction with polyT primers. Quantitative real-time PCR was performed using an ABI Prism 7000 (Applied Biosystems, Foster City, CA, USA) with ABI SYBR Green PCR Master Mix (Applied Biosystems), human GADPH as an internal control, and primers for YKL-40 (sense 5'-CCT GCT CAG CGC AGC ACT GT-3' and antisense 5'-GCT TTT GAC GCT TTC CTG GTC-3').

\section{ELISA for YKL-40 in the culture medium}

The amount of YKL-40 protein secreted by the cells was measured in the collected medium samples with a twosite sandwich-type ELISA (Quidel Corporation, San Diego, CA, USA) according to the manufacturer's instructions. Protein concentrations were determined as the absorbance measured using the Bio-Rad Benchmark Microplate Reader. No detectable YKL-40 was found in MEM containing $10 \%$ FBS. Each time point test was analyzed in triplicate.

\section{Western blotting}

U87 cells were treated with Res $(100 \mu \mathrm{M})$ and $20 \mu \mathrm{M}$ PD98059 (Calbiochem, San Diego, CA, USA) for $48 \mathrm{~h}$. DMSO (1:1000)-containing media served as vehicle. Western blotting was then performed as described previously [22] with primary antibodies against YKL-40 (R \& D Systems, Minneapolis, MN, USA), -actin, Phospho-ERK1/2, and ERK1/2 (Cell Signaling Technology, Beverly, MA, USA), followed by incubation for $1 \mathrm{~h}$ at room temperature with a secondary antibody (HRPconjugated anti-rat or anti-rabbit IgG; Cell Signaling Technology). Immunoreactive bands were visualized using enhanced chemiluminescence (Amersham Pharmacia Biotech, Buckinghamshire, UK) and quantified with LAS-1000 plus (Fujifilm, Tokyo, Japan).

\section{Statistical analysis}

All statistical analyses were performed with the Statistical Package for the Social Sciences (SPSS) 13.0 (SPSS inc., Chicago, IL). Statistical significance between more than 2 groups was determined using one-way ANOVA; statistical significance between 2 groups was determined using Student's $t$-test. The significance level of all tests was set at $P<0.05$

\section{Results}

Res-induced inhibition of cellular proliferation in U87 glioblastoma cells

Aggressive tumour cell proliferation is one of the most pronounced characteristics during the initiation and progression of gliomas. Because of Res' potent cancer chemopreventive effect in carcinogenesis, we first performed cell viability assays with WST-1 reagent. U87 cells were treated with increasing concentrations of Res (DMSO; 0, 1, 10, and $100 \mu \mathrm{M}$, and $1 \mathrm{mM}$ ) for different exposure times $(0,24,48$, and $72 \mathrm{~h}$ ) (Figure 1A). In general, the proliferation of U87 cells was inhibited by Res in both a dose- and time-dependent manner. However, $1 \mathrm{mM}$ Res was the maximum dosage for U87 cells. After being treated with $1 \mathrm{mM}$ Res for $24 \mathrm{~h}$, U87 cells exhibited the distinct features of cell death under the light microscope (data not shown). Interestingly, at $72 \mathrm{~h}$, $1 \mu \mathrm{M}$ Res treatment significantly $(P<0.01)$ inhibited 
A.

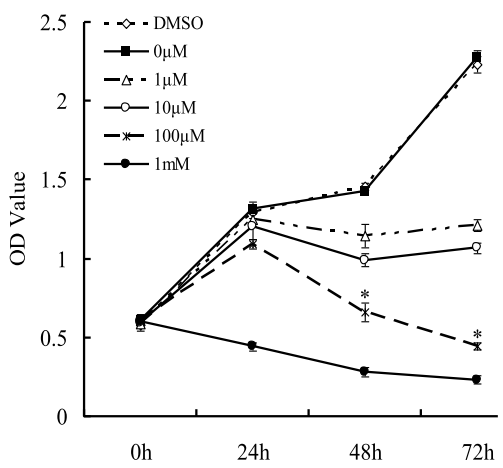

B.

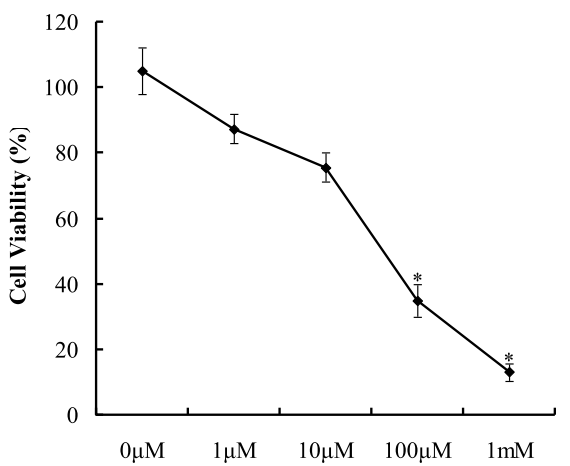

C.

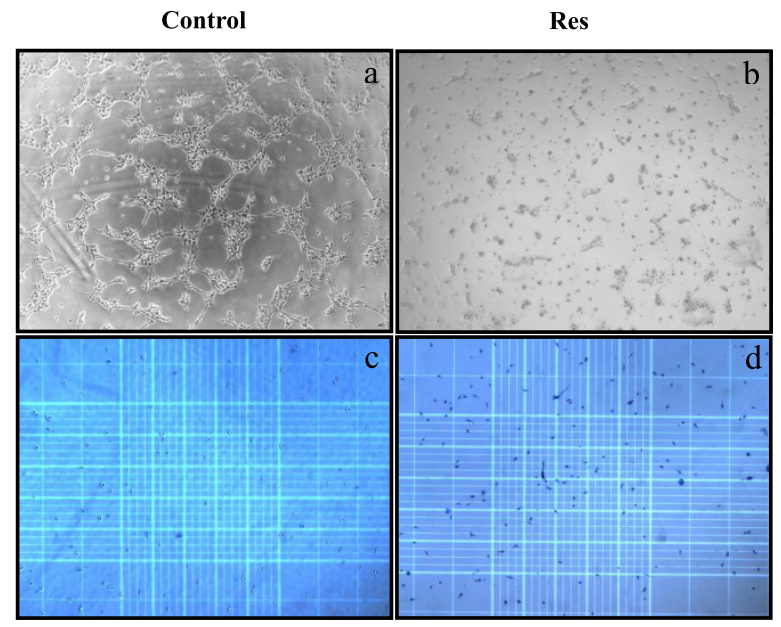

Figure 1 U87 cell proliferation assay. A. The WST-1 assay was performed to measure U87 cell viability after treatment with increasing concentrations of Res (DEMSO, $0,1,10$, and $100 \mu \mathrm{M}$, and $1 \mathrm{mM}$ ) for different exposure times $(0,24,48$, or $72 \mathrm{~h}$ ). The groups treated with 100 $\mu \mathrm{M}$ Res for 48 and $72 \mathrm{~h}$ showed the greatest significant difference compared with the other groups $(P<0.01)$. Asterisks indicate statistically significant changes $(P<0.01)$ after Res treatment. Bars indicate SE. B. The trypan blue dye exclusion assay revealed the U87 cell viability after treatment with increasing concentrations of Res $(0,1,10$, and $100 \mu \mathrm{M}$, and $1 \mathrm{mM})$ for $48 \mathrm{~h}$. Asterisks indicate statistically significant changes $(P<$ 0.01) after Res treatment. Bars indicate SE. C. Morphology of U87 cells treated by $100 \mu \mathrm{M}$ Res for $48 \mathrm{~h}$ under a light microscope (a.b);

Morphology of U87 cells treated by $100 \mu \mathrm{M}$ Res for $48 \mathrm{~h}$ in trypan blue dye cell exclusion assay (c.d). Original magnification: 40X.

cells compared to treatment with $0 \mu \mathrm{M}$. The groups treated with $100 \mu \mathrm{M}$ Res for 48 and $72 \mathrm{~h}$ exhibited the most statistically significant differences compared with those of the other groups $(P<0.01)$ although there was no significant difference between the 2 groups themselves $(P>0.05)$. At $48 \mathrm{~h}$, cell viability was further reinforced by the trypan blue dye exclusion assay (Figure 1B). Cell morphological changes are shown in Figure $1 C$. Therefore, we chose $100 \mu \mathrm{M}$ Res for $48 \mathrm{~h}$ as the critical point for further study.

\section{Res-induced decrease of U87 cell invasiveness}

It is well known that the highly invasive characteristics of malignant glioma cells account for the resultant poor therapeutic effects of radical excision. We assessed whether the invasiveness glioma cells can be inhibited by Res. U87 cells were pretreated with $100 \mu \mathrm{M}$ Res or $20 \mathrm{nM}$ YKL-40 siRNA for $48 \mathrm{~h}$. The same number of cells was seeded, and the invasiveness of the U87 cells was then determined in a modified Boyden chamber with a matrigel-precoated membrane filter insert. After 
A.

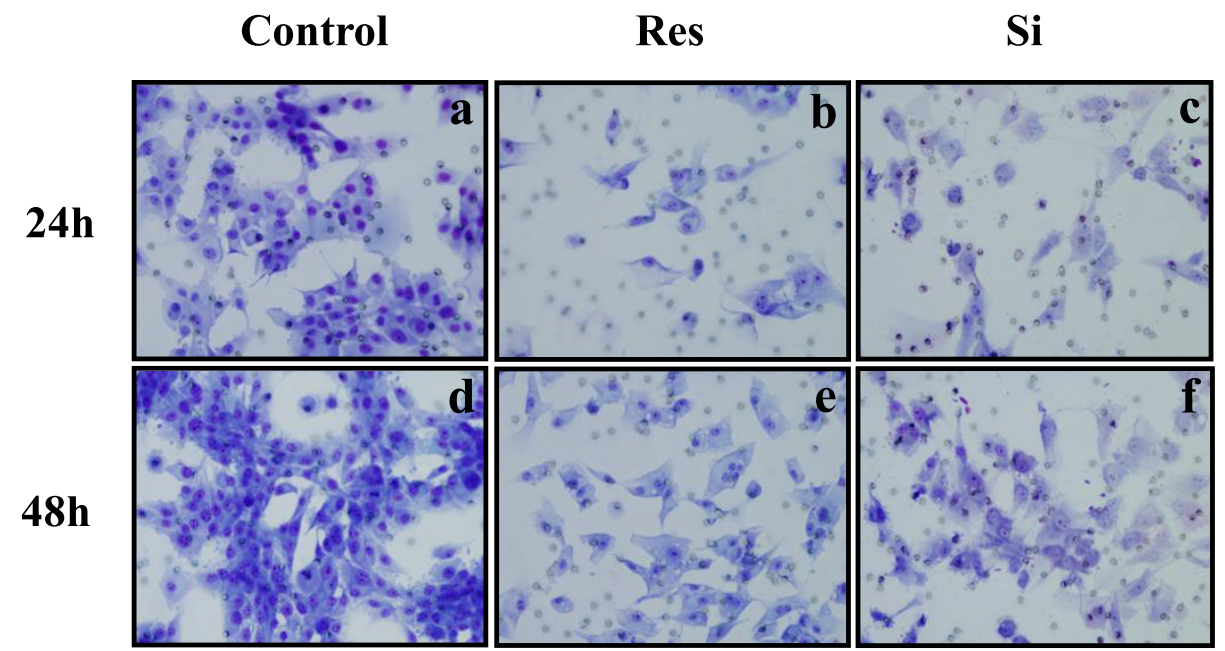

B.

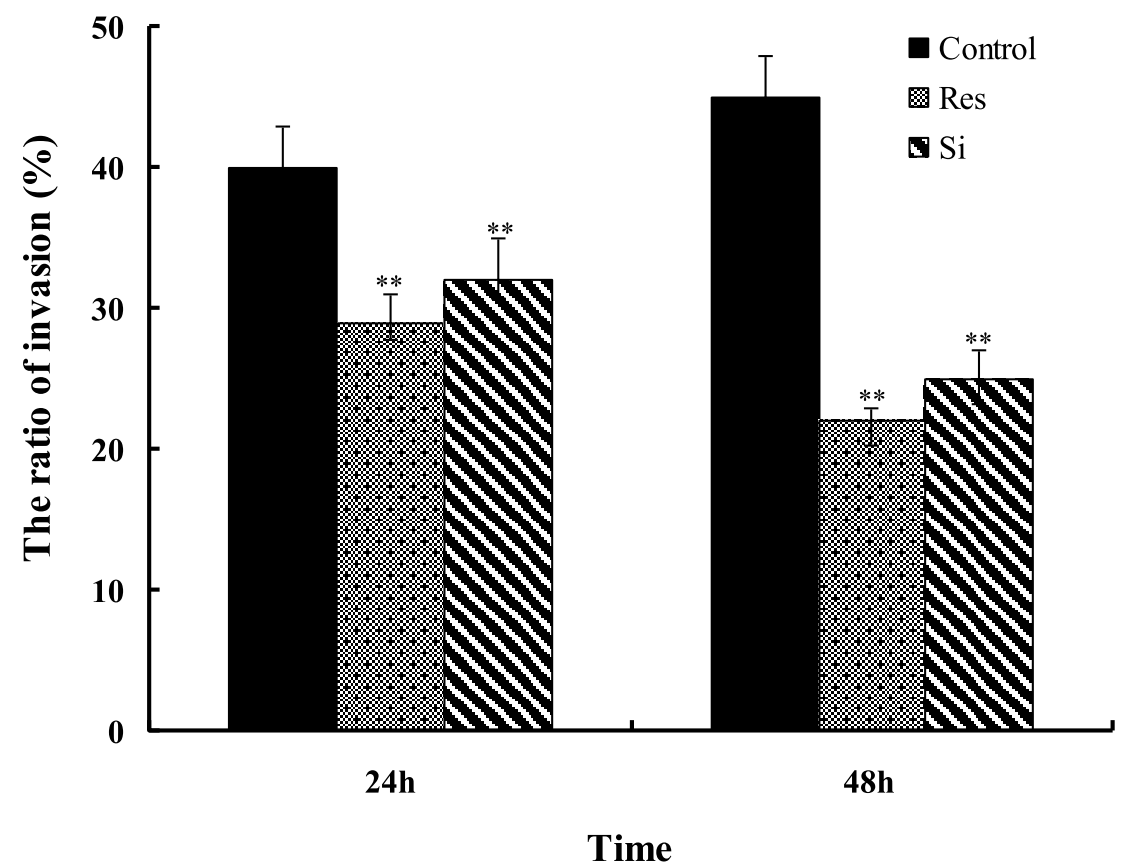

Figure 2 Matrigel invasion assay of U87 cells pretreated with $100 \mu \mathrm{M}$ Res and siRNA YKL-40 for $\mathbf{4 8} \mathrm{h}$. A. A modified Boyden chamber with a matrigel-precoated membrane filter insert was used to measure in vitro invasiveness. After 24 or $48 \mathrm{~h}$ of incubation, cells that invaded through the membrane were stained and representative fields were photographed. Original magnification: $200 \times$. B. Invasion was calculated as the ratio of the number of invading cells to total cell numbers in both sides of the membrane. The ratio of invading cells was significantly reduced by Res treatment. Asterisks indicate statistically significant changes $(P<0.01)$ after Res treatment. Columns represent the average number of invading cells per field of at least 5 fields from 3 independent experiments. Bars indicate SE. 
incubation for 24 or $48 \mathrm{~h}$, the ratio of invading cells decreased significantly $(P<0.01)$ (Figure 2$)$ in both Resand siRNA-pretreated U87 cells.

\section{Res-induced repression of YKL-40 promoter activity, mRNA transcription, and protein expression} In our previous study, the silencing of YKL- 40 inhibited the proliferation of U87 cells [21]. In conjunction with the cellular proliferation and invasion induced by Res in vitro, we further speculated that Res could decrease the expression of YKL-40. To test this hypothesis, YKL40 promoter was synthesized, and the luciferase assay was conducted. Real-time RT-PCR, western blotting, and ELISA were used to evaluate the mRNA transcription and protein expression levels. After treatment with $100 \mu \mathrm{M}$ Res for $48 \mathrm{~h}$, YKL-40 promoter activity was significantly reduced compared with that of the control group $(P<0.01)$ (Figure 3A). YKL-40 mRNA transcription and protein expression levels were consistently and steadily repressed in a time-dependent manner (Figure 3B-D). Thus, Res repressed YKL-40 in U87 cells by decreasing the activity of its promoter, mRNA transcription, and protein expression levels in vitro.

\section{Involvement of the ERK1/2 pathway in the Res-induced repression of YKL-40 expression}

Extracellular regulated kinase $1 / 2(E R K 1 / 2)$ is well known for its critical role in cell proliferation. In this study, we hypothesized that the ERK1/2 pathway is involved in the down-regulation of YKL-40 expression by Res. In order to demonstrate this, the specific inhibitor of the ERK1/2 pathway, PD98059 (20 $\mu \mathrm{M})$, was added along with $100 \mu \mathrm{M}$ Res to the U87 cell culture for $48 \mathrm{~h}$. The band densities of western blotting revealed that YKL-40 protein expression decreased most significantly in the Res-treated group $(P<0.01)$; in addition, PD98059 partially blocked the expression of YKL-40 (Figure 4A). Moreover, phosphor-ERK1/2 expression was reduced by Res treatment in a time-dependent manner (Figure 4B).

\section{Discussion}

The prominent hallmarks of gliomas are their characteristics of malignant proliferation and aggressive invasion. In a pioneering study, Nigro and colleagues determined that immortalized human astrocytes stably transfected with YKL-40 exhibited changes in gene expression similar to those observed in human tumours and confer radioresistance and an increased invasive capacity in vitro [17]. Our previous study showed that the YKL40 expression level was well correlated to the pathological grade of human primary astrocytomas and acted as a proliferation and anti-apoptosis factor in astrocytoma cells [21]. These findings suggest that YKL-40 is a

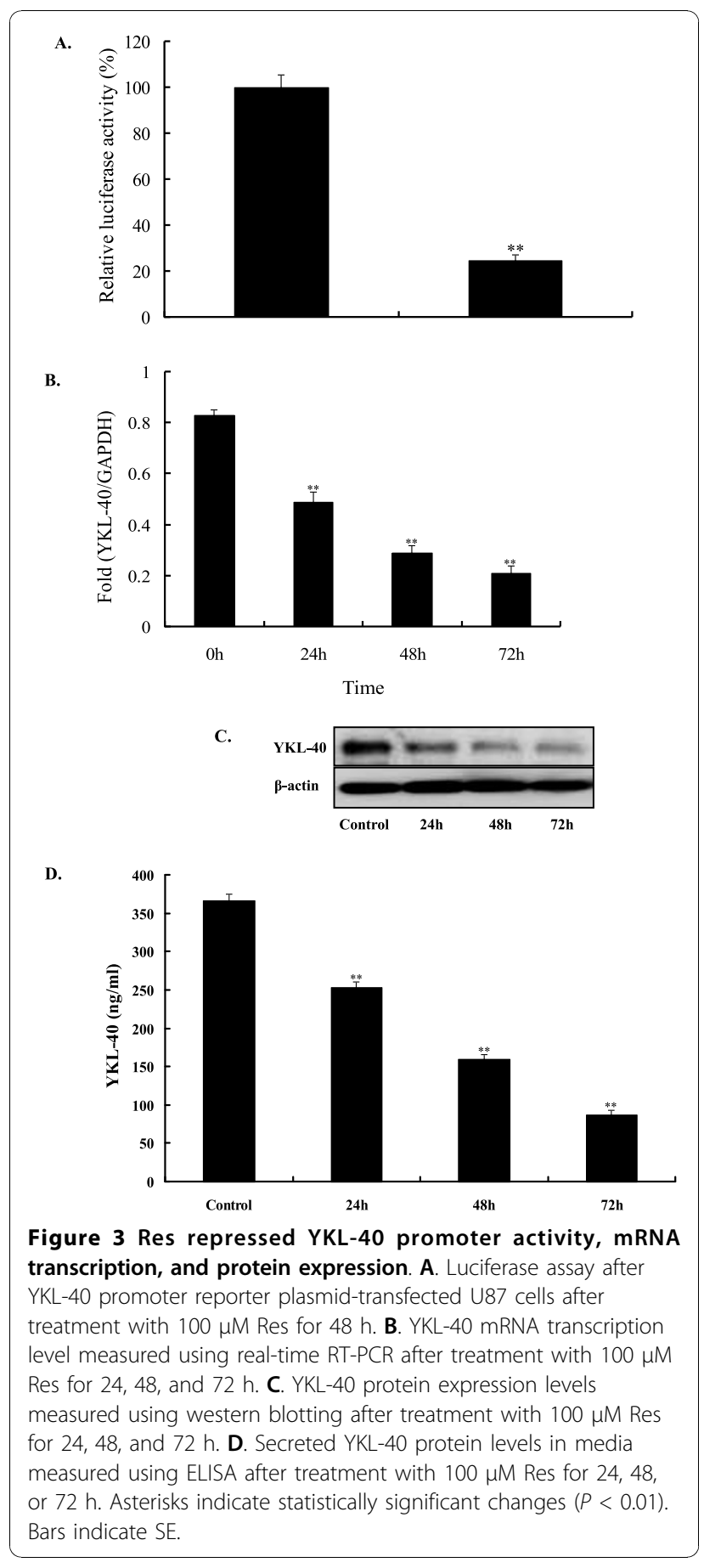

positive regulator in the proliferation and invasiveness of glioma cells. In the present study, we again determined that the invasion ability of U87 cells is sharply impaired after YKL-40 gene silencing. The numerous literary reviews and our accumulated findings suggest that YKL-40 is an attractive target for selective anticancer drug development. Our study reveals for the first time that a drug - Res - repressed the expression of YKL-40 


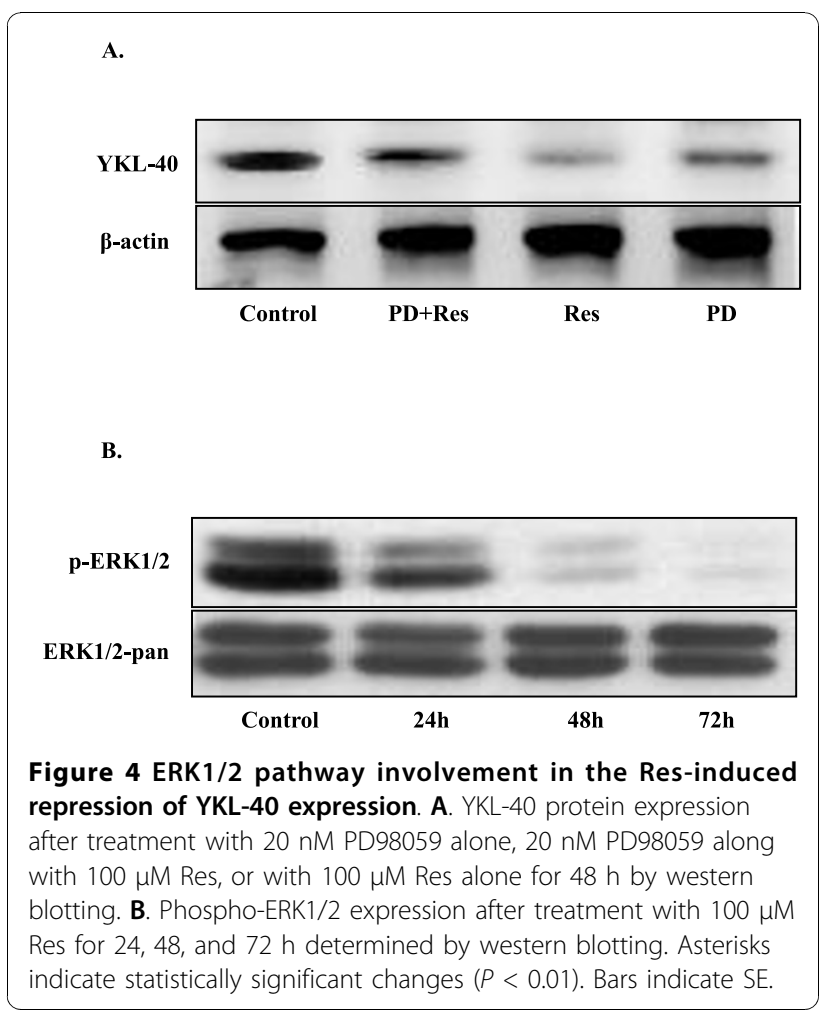

by decreasing its promoter activity, mRNA transcription, and protein expression levels in U87 cells in vitro.

It is widely known that Res is synthesized by a wide range of plant species, including grapes, peanuts, pines, and more than 70 other species in response to injury, ultraviolet irradiation, or fungal attack. In particular, Res is abundant in the skin of red grapes and may account for the "French Paradox" [25]. Due to its various beneficial health effects, such as its anti-oxidant, anti-inflammatory, and cardioprotective activities, Res is considered as a "state-of-the-art" medicine derived from natural sources [26-28]. However, it was not until 1997 when Jang and colleagues [25] published a seminal article demonstrating the anti-carcinogenic effects of Res did this phytoalexin attract considerable attention from oncologists as a novel chemopreventive agent. Shortly after, tremendous progress was made in revealing the potential role of Res in the anticarcinogenic process. Over the past decades, numerous preclinical findings indicate that Res inhibits the proliferation and induces apoptosis of various cancer cells cultured in vitro in addition to retarding the growth of implanted tumours in vivo [22-28]; this suggests the existence of an inverse relationship between Res and its striking inhibition associated with tumour initiation, promotion, and progression. Recent studies have also revealed that the chemopreventive effect of Res is significantly stronger than that of cisplatin (CP); furthermore, co-administration of Res $(20 \mathrm{mg} / \mathrm{kg})$ markedly enhances the chemoprevention of CP in the Ehrlich ascites carcinoma (EAC) solid tumour model [29]. Our current study further confirms that Res inhibits the proliferation of U87 cells in both a dose- and time-dependent manner. More interestingly, we demonstrated that Res significantly decreased the ability of U87 cells to invade in vitro. Thus, Res has promising roles in natural cancer prevention and treatment [30].

As the most distinct member of the mitogen-activated protein kinase (MAPK) family, the ERK pathway is synonymous with cell proliferation. YKL-40 expression is positively associated with the expression of phosphorERK1/2, which is strongly correlated with poor response to radiotherapy and negative outcomes [31]. In addition, phosphor-ERK $1 / 2$ expression is notably decreased in U87 cells in which YKL-40 is silenced [21]. Therefore, we speculate that the ERK1/2 pathway is involved in the down-regulation of YKL-40 induced by Res. The ERK1/2-specific inhibitor, PD98059 $(20 \mu \mathrm{M})$, was added along with $100 \mu \mathrm{M}$ Res to the culture medium and the U87 cells were cultured for $48 \mathrm{~h}$. As expected, YKL-40 expression decreased most significantly in the Res-treated group and partially decreased in PD98059-treated group. This indicates that the ERK $1 / 2$ pathway is involved in Res repressed YKL-40 expression in U87 cells. Moreover, the functional impact of Res on MAPK signaling may depend, to some extent, on the concentrations of Res used under different conditions and on the biological systems involved. Relatively low concentrations of Res $(1 \mathrm{pM}$ to $10 \mu \mathrm{M})$ are reported to induce phosphor-ERK1/2 in human neuroblastoma cells, whereas higher concentrations (50 to $100 \mu \mathrm{M})$ negatively interfere with MAPK phosphorylation [32]. In human coronary smooth muscle cells (HCSMC), pretreatment with Res $(1-100 \mu \mathrm{M})$ triggered marked inhibition of endothelin-1-evoked cell proliferation and ERK1/2 activation [33]. In the present study, we consistently used $100 \mu \mathrm{M}$ Res and observed significantly decreased phosphor-ERK1/2 activity in a time-dependent manner.

\section{Conclusion}

Our study demonstrates for the first time that Res represses YKL-40 expression by decreasing its promoter activity, mRNA transcription, and protein expression levels in U87 cells in vitro; in addition, the ERK1/2 pathway is involved in this process. This finding supports the idea of targeting YKL- 40 as a novel adjuvant therapy in glioma treatment and expands the prospective use of Res in anti-glioma research. We hope that any drug that specifically inhibits the expression of YKL-40 might enhance the effects of tumour excision of and improve the prognosis for glioma patients. 


\section{Abbreviations}

MAPK: mitogen-activated protein kinase; ERK1/2: extracellular regulated kinase 1/2; Res: resveratrol; ELISA: enzyme linked immunosorbent assay; MEM: minimum essential medium; siRNA: short interference RNA

\section{Acknowledgements}

This study was supported by a grant from the Foundation of Japan Ministry of Education, Science, Sports, Culture, and Technology (No. 22390277), Kagawa University Characteristic Prior Research Fund 2009, and the National Natural Science Foundation of China (No. 30870843). We thank our emeritus Prof. Seigo Nagao for his great spiritual inspiration. We thank Prof. You-hui Zhang for his help in revising the manuscript. We thank Ms. Sachiyo Ishihara, Ms. Tomiyo Kashihara, Ms. Naoko Iwasaki, and Ms. Ayumi Kawasaki for preparing the materials. We also thank Ms. Julie Yamamoto for editorial assistance.

\section{Author details}

'Department of Neurosurgery, Xijing Hospital, The Fourth Military Medical University, 127 West Changle Road, Xi'an, Shaanxi Province, 710032, People's Republic of China. ${ }^{2}$ Department of Neurological Surgery, Faculty of Medicine, Kagawa University, 1750-1 Ikenobe, Miki-cho, Kida-gun, Kagawa 761-0793, Japan. ${ }^{3}$ Division of Endocrinology and Metabolism, Department of Internal Medicine, Faculty of Medicine, Kagawa University, 1750-1 Ikenobe, Miki-cho, Kida-gun, Kagawa 761-0793, Japan. ${ }^{4}$ Department of Pharmacology, Faculty of Medicine, Kagawa University, 1750-1 Ikenobe, Miki-cho, Kida-gun, Kagawa 761-0793, Japan

\section{Authors' contributions}

WZ, KMu, and XZ designed and performed the study. KMa synthesized the YKL-40 promoter. SD performed real-time RT-PCR. MO, KMi, and NK were responsible for protein analysis. ZF and $\Pi$ were responsible for the preparation of the manuscript. All authors read and approved the final manuscript.

\section{Competing interests}

The authors declare that they have no competing interests.

Received: 2 March 2010 Accepted: 28 October 2010 Published: 28 October 2010

\section{References}

1. Tamiya T, Takao S, Ichikawa T, Chayama K, Date I: Successful chemotherapy for congenital malignant gliomas: a report of two cases. Pediatr Neurosurg 2006, 42:240-244.

2. Tamiya T, Kinoshita K, Ono Y, Matsumoto K, Furuta T, Ohmoto T: Proton magnetic resonance spectroscopy reflects cellular proliferative activity in astrocytomas. Neuroradiology 2000, 42:333-338.

3. Jensen BV, Johansen JS, Price PA: High levels of serum HER-2/neu and YKL-40 independently reflect aggressiveness of metastatic breast cancer. Clin Cancer Res 2003, 9:4423-4434.

4. Cintin C, Johansen JS, Christensen IJ, Price PA, Sørensen S, Nielsen HJ: Serum YKL-40 and colorectal cancer. Br J Cancer 1999, 79:1494-1499.

5. Johansen JS, Drivsholm L, Price PA, Christensen IJ: High serum YKL-40 leve in patients with small cell lung cancer is related to early death. Lung Cancer 2004, 46:333-340.

6. Brasso K, Christensen IJ, Johansen JS, Teisner B, Garnero P, Price PA, Iversen P: Prognostic value of PINP, bone alkaline phosphatase, CTX-I, and YKL-40 in patients with metastatic prostate carcinoma. Prostate 2006, 66:503-513.

7. Høgdall EV, Johansen JS, Kjaer SK, Price PA, Christensen L, Blaakaer J, Bock JE, Glud E, Høgdall CK: High plasma YKL-40 level in patients with ovarian cancer stage III is related to shorter survival. Oncol Rep 2003, 10:1535-1538.

8. Schmidt H, Johansen JS, Gehl J, Geertsen PF, Fode K, von der Maase H: Elevated serum level of YKL-40 is an independent prognostic factor for poor survival in patients with metastatic melanoma. Cancer 2006, 106:1130-1139.

9. Schmidt H, Johansen JS, Sjoegren P, Christensen IJ, Sorensen BS, Fode K, Larsen J, von der Maase $\mathrm{H}$ : Serum YKL-40 predicts relapse-free and overall survival in patients with American Joint Committee on Cancer stage I and II melanoma. J Clin Oncol 2006, 24:798-804.
10. Tanwar MK, Gilbert MR, Holland EC: Gene expression microarray analysis reveals YKL-40 to be a potential serum marker for malignant character in human glioma. Cancer Res 2002, 62:4364-4368.

11. Hormigo A, Gu B, Karimi S, Riedel E, Panageas KS, Edgar MA, Tanwar MK, Rao JS, Fleisher M, DeAngelis LM, Holland EC: YKL-40 and matrix metalloproteinase- 9 as potential serum biomarkers for patients with high-grade gliomas. Clin Cancer Res 2006, 12:5698-5704.

12. Roslind A, Johansen JS, Christensen IJ, Kiss K, Balslev E, Nielsen DL, Bentzen J, Price PA, Andersen E: High serum levels of YKL-40 in patients with squamous cell carcinoma of the head and neck are associated with short survival. Int J Cancer 2008, 122:857-863.

13. Johansen JS, Bojesen SE, Mylin AK, Frikke-Schmidt R, Price PA Nordestgaard BG: Elevated plasma YKL-40 predicts increased risk of gastrointestinal cancer and decreased survival after any cancer diagnosis in the general population. J Clin Oncol 2009, 27:572-578.

14. Johansen JS, Williamson MK, Rice JS, Price PA: Identification of proteins secreted by human osteoblastic cells in culture. J Bone Miner Res 1992, 7:501-512

15. Hakala BE, White $C$, Recklies AD: Human cartilage gp-39, a major secretory product of articular chondrocytes and synovial cells, is a mammalian member of a chitinase protein family. J Biol Chem 1993, 268:25803-25810.

16. Rehli M, Niller HH, Ammon C, Langmann S, Schwarzfischer L, Andreesen R, Krause SW: Transcriptional regulation of $\mathrm{CHI} 3 \mathrm{~L} 1$, a marker gene for late stages of macrophage differentiation. J Biol Chem 2003, 278:44058-44067.

17. Nigro JM, Misra A, Zhang L, Smirnov I, Colman H, Griffin C, Ozburn N, Chen M, Pan E, Koul D, Yung WK, Feuerstein BG, Aldape KD: Integrated array-comparative genomic hybridization and expression array profiles identify clinically relevant molecular subtypes of glioblastoma. Cancer Res 2005, 65:1678-1686.

18. Bonneh-Barkay D, Bissel SJ, Wang G, Fish KN, Nicholl GC, Darko SW, MedinaFlores R, Murphey-Corb M, Rajakumar PA, Nyaundi J, et al: YKL-40, a marker of simian immunodeficiency virus encephalitis, modulates the biological activity of basic fibroblast growth factor. Am J Pathol 2008, 173:130-143.

19. Shao R, Hamel K, Petersen L, Cao QJ, Arenas RB, Bigelow C, Bentley B, Yan WY: KL-40, a secreted glycoprotein, promotes tumor angiogenesis. Oncogene 2009, 28:4456-4468.

20. Shostak K, Labunskyy V, Dmitrenko V, Malisheva T, Shamayev M, Rozumenko V, Zozulya Y, Zehetner G, Kavsan V: HC gp-39 gene is upregulated in glioblastomas. Cancer Lett 2003, 198:203-210.

21. Zhang W, Kawanishi M, Miyake K, Kagawa M, Kawai N, Nagao S, Nishiyama A, Fei Z, Zhang X, Tamiya T: Association between YKL-40 and adult primary astrocytoma. Cancer 2010, 116:2688-2697.

22. Zhang $W$, Fei Z, Zhen $H$, Zhang J, Zhang X: Resveratrol inhibits cell growth and induces apoptosis of rat C6 glioma cells. J Neurooncol 2007 81:231-240.

23. Tseng SH, Lin SM, Chen JC, Su YH, Huang HY, Chen CK, Lin PY, Chen Y: Resveratrol suppresses the angiogenesis and tumour growth of gliomas in rats. Clin Cancer Res 2004, 10:2190-2202.

24. Renaud S, de Lorgeril M: Wine, alcohol, platelets, and the French paradox for coronary heart disease. Lancet 1992, 339:1523-1526.

25. Jang M, Cai L, Udeani GO, Slowing KV, Thomas CF, Beecher CW, Fong HH, Farnsworth NR, Kinghorn AD, Mehta RG, et al: Cancer chemopreventive activity of resveratrol, a natural product derived from grapes. Science 1997, 275:21-220.

26. Uenobe $S$, Nakamura S, Miyazawa M: Antimutagenic effect of resveratrol against Trp-P-1. Mutation Res 1997, 373:197-200.

27. Baur JA, Sinclair DA: Therapeutic potential of resveratrol: The in vivo evidence. Nat Rev Drug Discov 2006, 5:493-506.

28. Brakenhielm E, Cao R, Cao Y: Suppression of angiogenesis, tumour growth, and wound healing by resveratrol, a natural compound in red wine and grapes. FASEB J 2001, 15:1798-1800.

29. El-Mowafy AM, El-Mesery ME, Salem HA, Al-Gayyar MM, Darweish MM: Prominent chemopreventive and chemoenhancing effects for resveratrol: unraveling molecular targets and the role of C-reactive protein. Chemotherapy 2010, 56:60-65.

30. Kundu JK, Surh YJ: Cancer chemopreventive and therapeutic potential of resveratrol: mechanistic perspectives. Cancer Lett 2008, 269:243-261.

31. Pelloski CE, Lin E, Zhang L, Yung WK, Colman H, Liu JL, Woo SY, Heimberger AB, Suki D, Prados M, et al: Prognostic associations of activated mitogen-activated protein kinase and Akt pathways in glioblastoma. Clin Cancer Res 2006, 12:3935-3941. 
32. Miloso M, Bertelli A, Nicolini G, Tredici G: Resveratrol-induced activation of the mitogen-activated protein kinases, ERK1 and ERK2, in human neuroblastoma SH-SY5Y cells. Neurosci Lett 1999, 264:141-144.

33. El-Mowafy AM, Alkhalaf M, Nassar NN: Resveratrol reverses ET-1-evoked mitogenic effects in human coronary arterial cells by activating the kinase-G to inhibit ERK-enzymes. Int J Cardiol 2009, 136:263-269.

Pre-publication history

The pre-publication history for this paper can be accessed here: http://www.biomedcentral.com/1471-2407/10/593/prepub

doi:10.1186/1471-2407-10-593

Cite this article as: Zhang et al:: Resveratrol represses YKL-40 expression in human glioma U87 cells. BMC Cancer 2010 10:593.

Submit your next manuscript to BioMed Central and take full advantage of:

- Convenient online submission

- Thorough peer review

- No space constraints or color figure charges

- Immediate publication on acceptance

- Inclusion in PubMed, CAS, Scopus and Google Scholar

- Research which is freely available for redistribution

Submit your manuscript at www.biomedcentral.com/submit
C Biomed Central 